\title{
The predictive value of tumor mutation burden for immune checkpoint inhibitors therapy in non-small cell lung cancer is affected by patients' age
}

\author{
Yongfeng $\mathrm{Wu}^{1}$, Jinming $\mathrm{Xu}^{1}$, Jiawei $\mathrm{Xu}^{2}$, Yiqing Wang ${ }^{1}$, Luming Wang ${ }^{1}$, Wang $\mathrm{Lv}^{1}$ and Jian $\mathrm{Hu}^{1 *}$
}

\begin{abstract}
High tumor mutation burden (TMB), which is associated with increased tumor immunogenicity, has been identified to predict improved response to immune checkpoint inhibitors (ICls) therapy in non-small cell lung cancer (NSCLC). As host immunity is also significant to eliminate cancer cells, however, its clinical impact on cancer immunotherapy is still largely unknown. Here we explored the influence of age, which is an important characteristic to evaluate immune response of patients, on TMB-based predictive system for ICls therapy in NSCLC. Our results showed that high TMB was capable of predicting better durable clinical benefit (DCB) in age ${ }^{\text {low }}$ group, while it was insignificant in age ${ }^{\text {high }}$ group. Besides, the predictive power of TMB for progression-free survival (PFS) and overall survival (OS) was better in age ${ }^{\text {low }}$ group than in age ${ }^{\text {high }}$ group. Our study illustrated that the predictive value of TMB for ICls therapy was better in young patients than in elderly patients in NSCLC.
\end{abstract}

Keywords: Tumor mutation burden, TMB, Age, Immune checkpoint inhibitor, ICI, NSCLC, Immunosenescence

To the Editor,

Tumor mutation burden (TMB) is widely demonstrated to predict the efficacy of immune checkpoint inhibitors (ICIs) in diverse cancers, especially in nonsmall cell lung cancer (NSCLC) and melanoma $[1,2]$. High TMB presents enriched clonal neoantigens and increased tumor immunogenicity, which can improve the response to cancer immunotherapy [3]. However, as host immunity is also significant to eliminate cancer cells, its clinical impact on cancer immunotherapy is still largely unknown. Immunosenescence, which refers to the decline of immune system with aging, may contribute to reduced tumor cell clearance

\footnotetext{
* Correspondence: dr_hujian@zju.edu.cn

'Department of Thoracic Surgery, The First Affiliated Hospital, School of Medicine, Zhejiang University, 79 Qingchun Road, Hangzhou 310003, China Full list of author information is available at the end of the article
}

efficiency in body, leading to increased cancer incidence in the elderly [4].

Based on these facts and evidence, we hypothesized that TMB could show better predictive value for cancer immunotherapy in young patients than in elderly patients in NSCLC. In order to test the hypothesis, published clinical data was identified through systematic literature search. Durable clinical benefit (DCB), progression-free survival (PFS) and overall survival (OS) were adopted as endpoints for assessment. Detailed methods were explained in Additional file 1.

We identified three NSCLC immunotherapy cohorts containing 665 patients $[1,5,6]$. Detailed characteristics of patients included were summarized in Additional file 2: Table S1.

Firstly, as was shown in Fig. 1, high TMB was capable of predicting better DCB in age ${ }^{\text {low }}$ group. However, the predictive power was insignificant in age ${ }^{\text {high }}$ 


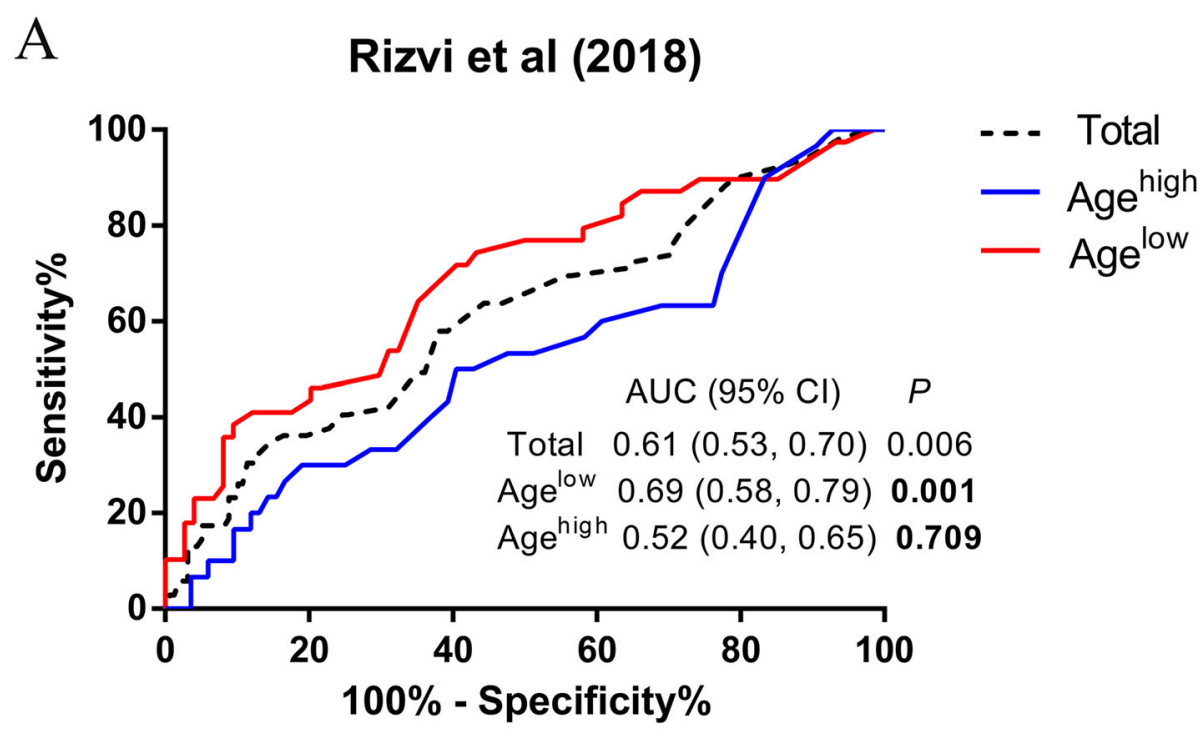

$\mathrm{B}$

\section{Hellmann et al (2018)}

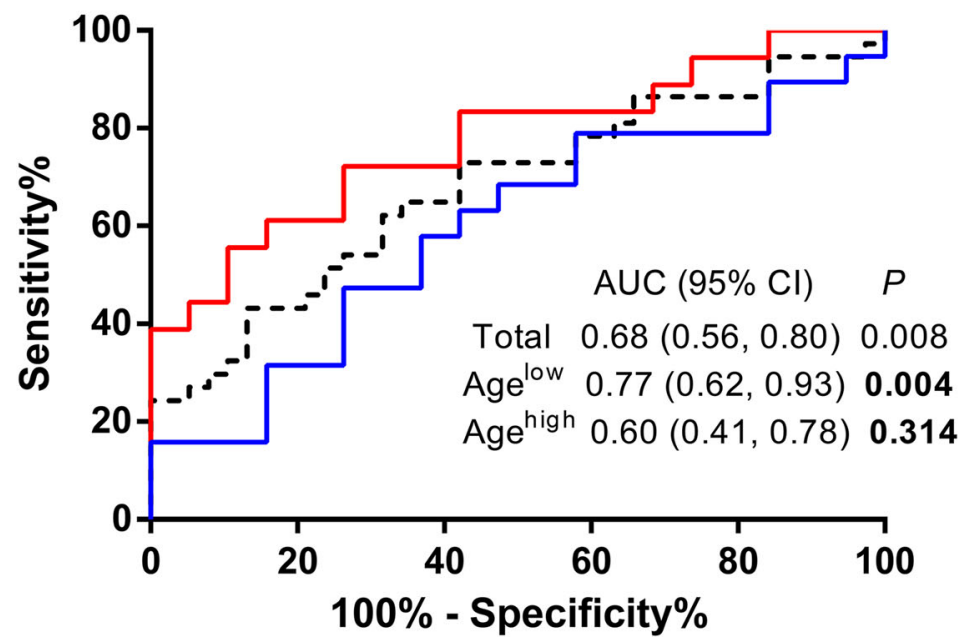

Fig. 1 ROC curve analysis of the association between TMB and DCB in young and elderly patients in NSCLC. ROC curves of (a) Rizvi cohort, (b) Hellmann cohort. ROC: receiver operator characteristic; TMB: tumor mutation burden; DCB: durable clinical benefit; NSCLC: non-small cell lung cancer; AUC: area under curve; Cl: confidence interval

group, indicating high TMB failed to forecast clinical benefit in the group.

Secondly, it was found that in age ${ }^{\text {low }}$ group, high TMB dramatically illustrated improved PFS (Rizvi cohort: Hazard ratio [HR] 0.55, 95\% confidence interval $[\mathrm{CI}]$ 0.35, 0.80, $P=0.003$, Fig. 2a; Hellman cohort: HR 0.26, 95\% CI 0.08, 0.45, $P<0.001$, Fig. $2 \mathrm{c})$. The results were still significant in multivariate analysis (Rizvi cohort: Adjusted HR 0.54, 95\% CI 0.36, 0.82, $P=0.004$; Hellman cohort: Adjusted HR 0.23 , 95\% CI $0.09,0.55, P=0.001)$. However, there was no correlation between PFS and TMB level in age $^{\text {high }}$ group (Rizvi cohort: HR 1.03, 95\% CI 0.70, 1.51, $P=0.898$, Fig. 2b; Hellman cohort: HR 0.71,
95\% CI $0.32,1.55, P=0.388$, Fig. $2 d$ ). In the adjusted model, the conclusion was unchanged (Rizvi cohort: Adjusted HR 1.10, 95\% CI 0.71, 1,71, $P=$ 0.677; Hellman cohort: Adjusted HR 0.60, 95\% CI $0.24,1.50, P=0.275)$. Then, the result of metaanalysis further illustrated that predictive power of TMB was more significant in age ${ }^{\text {low }}$ group than in age $^{\text {high }}$ group (Heterogeneity between two groups: $P=0.007$, Fig. 3). In addition, in order to exclude whether the specific cutoff of TMB had an effect on the result, TMB at the highest quarter was adopted as another cutpoint. As was shown in Additional file 2: Figure S1, high TMB still showed better predictive power of PFS in age ${ }^{\text {low }}$ group rather than in 


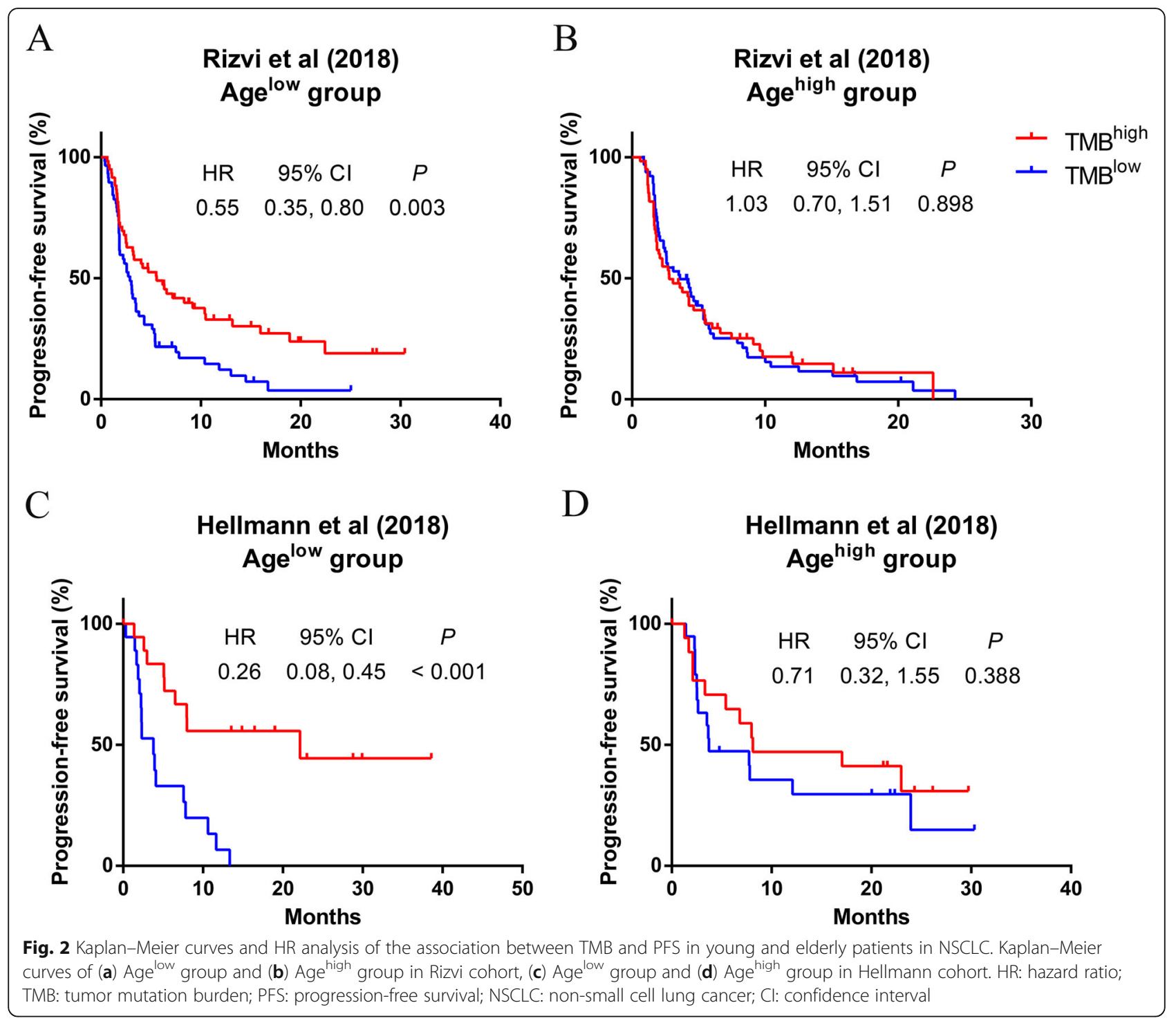

age $^{\text {high }}$ group (Heterogeneity between two groups: $P=0.012)$.

Moreover, the predictive value of TMB for OS of immunotherapy was evaluated in the two age groups. When using median TMB as cutoff, though both age $^{\text {low }}$ (HR 0.72, 95\% CI 0.46, 1.07, $P=0.112$, Additional file 2: Figure S2A) and age ${ }^{\text {high }}$ (HR 1.03, 95\% CI $0.72,1.47, P=0.881$, Additional file 2: Figure S2B) groups showed insignificant predictive value, the former presented a better tendency. When adopting TMB at the highest quarter as cutpoint, high TMB illustrated meaningful predictive power in age $\mathrm{e}^{\text {low }}$ group (HR 0.43, 95\% CI 0.30, 0.76, $P=0.007$, Additional file 2: Figure S2C), while it

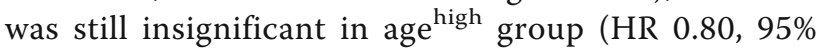
CI $0.53,1.19, P=0.282$, Additional file 2 : Figure $\mathrm{S} 2 \mathrm{D})$. In multivariate analysis, the conclusion was unchanged (Age ${ }^{\text {low }}$ group: Adjusted HR 0.43, 95\%
CI 0.24, 0.75, $P=0.003$; Age $\mathrm{e}^{\text {high }}$ group: Adjusted HR $0.82,95 \%$ CI $0.54,1.25, P=0.354$ ).

In the present study, we found that TMB could present better predictive value on the response to cancer immunotherapy in young patients than in elderly patients in NSCLC. High TMB is associated with enhanced tumor immunogenicity [3], which is an important factor in determining efficacy of cancer immunotherapy [7]. However, in addition to sufficient antigen presentation, a dynamic host immunity may also be necessary for eliminating cancer cells during ICIs therapy. In the process of aging, immune cells are gradually reduced in quantity and becoming defective [4]. Interestingly, PD-1/PD-L1 blockade could not completely restore exhausted $\mathrm{T}$-cell responses in aged mice [8], suggesting the significance of basic immunity of host to confront tumor. To note, age itself may not be an appropriate marker to predict cancer 


\begin{tabular}{|c|c|c|}
\hline \multirow{2}{*}{$\begin{array}{l}\text { Study } \\
\text { ID }\end{array}$} & \multirow[b]{2}{*}{$\mathrm{HR}(95 \% \mathrm{CI})$} & \multirow{2}{*}{$\begin{array}{l}\% \\
\text { Weight }\end{array}$} \\
\hline & & \\
\hline \multicolumn{3}{|l|}{ Age-low group } \\
\hline Rizvi et al (2018) & $0.55(0.35,0.80)$ & 37.60 \\
\hline Hellmann et al (2018) & $0.26(0.08,0.45)$ & 8.61 \\
\hline Subtotal $(\mathrm{I}-\mathrm{squared}=57.5 \%, \mathrm{p}=0.125)$ & $0.48(0.33,0.69)$ & 46.21 \\
\hline \multicolumn{3}{|l|}{ Age-high group } \\
\hline Rizvi et al (2018) & $1.03(0.70,1.51)$ & 43.47 \\
\hline Hellmann et al (2018) & $0.71(0.32,1.55)$ & 10.32 \\
\hline Subtotal $(I-$ squared $=0.0 \%, p=0.406)$ & $0.96(0.68,1.35)$ & 53.79 \\
\hline \multicolumn{3}{|l|}{ Heterogeneity between groups: $p=0.007$} \\
\hline Overall $(\mathrm{I}-$ squared $=70.7 \%, \mathrm{p}=0.017)$ & $0.70(0.54,0.90)$ & 100.00 \\
\hline & & \\
\hline
\end{tabular}

immunotherapy response due to its complex influence on body besides host immunity [9].

There are several strengths in the study. Firstly, different studies including a large number of patients were analyzed, which increased the credibility of the results. Besides, both univariate and multivariate analyses were adopted, which improved the accuracy of the conclusion. However, there are quite a few limitations in the present study. First of all, different TMB testing methodologies and cutoffs were utilized, as there is still no uniform standard, which could lead to heterogeneity of the results. In addition, analysis in the study was conducted only in NSCLC, while related open access data in most cancers are still insufficient.

In conclusion, we revealed that the predictive power of TMB on ICIs therapy was better in young patients than in elderly patients in NSCLC. Therefore, more effective markers need to be identified to differentiate the efficacy of cancer immunotherapy in elderly patients in NSCLC. In addition, the combination of tumor immunogenicity and host immunity evaluation may better identify patient subgroups which are suitable for cancer immunotherapy.

\section{Supplementary information}

Supplementary information accompanies this paper at https://doi.org/10. 1186/s40364-020-00188-2.

Additional file 1. Supplementary Methods

Additional file 2: Table S1. Clinical characteristics of included NSCLC cohorts treated with immune checkpoint inhibitors. Figure S1. Forest plot of the association between TMB (using the highest quarter as cutoff) and PFS in young and elderly patients in NSCLC. Figure S2. KaplanMeier curves and HR analysis of the association between TMB and OS in young and elderly patients in NSCLC. Kaplan-Meier curves of (A-B) using median TMB as cutoff and (C-D) using the highest quarter as cutoff.

\section{Abbreviations}

TMB: Tumor mutation burden; ICls: Immune checkpoint inhibitors; NSCLC: Non-small cell lung cancer; DCB: Durable clinical benefit; PFS: Progression-free survival; OS: Overall survival; HR: Hazard ratio; Cl: Confidence interval; ROC: Receiver operator characteristic; AUC: Area under curve

\section{Acknowledgements}

Not applicable.

\section{Authors' contributions}

$\mathrm{JH}$ contributed to the conception and design of the work. YFW contributed to conception, design, data analysis and editing the manuscript. JMX and JWX contributed to design and data analysis. YQW, LW, and WL contributed 
to data acquisition and critical revision of the manuscript. All authors read and approved the final manuscript.

\title{
Funding
}

This study was funded by National Key R\&D Program of China (No. 2017YFC0113500), Major Science and Technology Projects of Zhejiang Province (No. 2014C03032), Lung Cancer Diagnosis and Treatment Technology Research Center of Zhejiang Province (JBZX-202007), Key Disciplines of Traditional Chinese Medicine in Zhejiang Province (No. 2017XK-A33).

\section{Availability of data and materials}

The datasets analyzed during the current study are available at cBioPortal (Samstein et al. (2019): https://www.cbioportal.org/study/summary?id=tmb_ mskcc_2018 [1]; Rizvi et al. (2018): https://www.cbioportal.org/study/ summary?id=nsclc_pd1_msk_2018 [5]) and ScienceDirect (Hellmann et al. (2018): https://doi.org/10.1016/j.ccell.2018.03.018 [6]).

\section{Ethics approval and consent to participate}

\author{
Not applicable.
}

\section{Consent for publication}

Not applicable.

\section{Competing interests}

The authors declare that they have no competing interests.

\section{Author details}

'Department of Thoracic Surgery, The First Affiliated Hospital, School of Medicine, Zhejiang University, 79 Qingchun Road, Hangzhou 310003, China. ${ }^{2}$ Department of Toxicology, School of Public Health, School of Medicine,

Zhejiang University, Hangzhou 310058, China.

Received: 22 December 2019 Accepted: 18 March 2020

Published online: 09 April 2020

\section{References}

1. Samstein RM, Lee C-H, Shoushtari AN, Hellmann MD, Shen R, Janjigian YY, et al. Tumor mutational load predicts survival after immunotherapy across multiple cancer types. Nat Genet. 2019;51(2):202-6.

2. Wu Y, Xu J, Du C, Wu Y, Xia D, Lv W, et al. The predictive value of tumor mutation burden on efficacy of immune checkpoint inhibitors in cancers: a systematic review and meta-analysis. Front Oncol. 2019;9:1161.

3. McGranahan N, Furness AJS, Rosenthal R, Ramskov S, Lyngaa R, Saini SK, et al. Clonal neoantigens elicit T cell immunoreactivity and sensitivity to immune checkpoint blockade. Science. 2016;351(6280):1463-9.

4. Elias R, Hartshorn K, Rahma O, Lin N, Snyder-Cappione JE. Aging, immune senescence, and immunotherapy: a comprehensive review. Semin Oncol. 2018;45(4):187-200.

5. Rizvi H, Sanchez-Vega F, La K, Chatila W, Jonsson P, Halpenny D, et al. Molecular determinants of response to anti-programmed cell death (PD)-1 and anti-programmed death-ligand 1 (PD-L1) blockade in patients with non-small-cell lung Cancer profiled with targeted next-generation sequencing. J Clin Oncol. 2018;36(7):633-41.

6. Hellmann MD, Nathanson T, Rizvi H, Creelan BC, Sanchez-Vega F, Ahuja A, et al. Genomic Features of Response to Combination Immunotherapy in Patients with Advanced Non-Small-Cell Lung Cancer. Cancer Cell. 2018;33(5): 843-52 e4.

7. Chowell D, Morris LGT, Grigg CM, Weber JK, Samstein RM, Makarov V, et al. Patient HLA class I genotype influences cancer response to checkpoint blockade immunotherapy. Science. 2018;359(6375):582-7.

8. Lages CS, Lewkowich I, Sproles A, Wills-Karp M, Chougnet C. Partial restoration of T-cell function in aged mice by in vitro blockade of the PD-1/ PD-L1 pathway. Aging Cell. 2010;9(5):785-98.

9. Pawelec G. Does patient age influence anti-cancer immunity? Semin Immunopathol. 2019;41(1):125-31.

\section{Publisher's Note}

Springer Nature remains neutral with regard to jurisdictional claims in published maps and institutional affiliations.

Ready to submit your research? Choose BMC and benefit from:

- fast, convenient online submission

- thorough peer review by experienced researchers in your field

- rapid publication on acceptance

- support for research data, including large and complex data types

- gold Open Access which fosters wider collaboration and increased citations

- maximum visibility for your research: over $100 \mathrm{M}$ website views per year

At BMC, research is always in progress.

Learn more biomedcentral.com/submissions 